Michael Hauser**

\title{
Badiou and the Ontological Limits of Mathematics'
}

Mathematical axioms are not axioms of general truth. [...] But the mathematician argues, from his finite truths, through habit, as if they were of an absolutely general applicability as the world indeed imagines them to be.

E.A. Poe, The Purloined Letter

\section{Philosophy and the composition of its mathematical condition}

In the history of philosophy we can find various ways of philosophy relating to mathematics (Eleats, the Atomists, Plato, Descartes, Leibniz, etc.). In keeping with this tradition, Badiou constituted a new relationship between philosophy and mathematics. In Badiou's words, "mathematics can tell us something about being as such, without knowing that this is the very meaning of mathematics." This relationship formed a new position of philosophy regarding mathematics, which I will gradually elucidate.

Mathematics in the shape of set theory was the science to which Badiou related philosophy in Being and Event, providing the thesis that mathematics is ontology (the science of being). "Insofar as being, qua being, is nothing other than pure multiplicity, it is legitimate to say that ontology, the science of being qua being, is nothing other than mathematics itself." 3 Badiou understood the Zermelo-Fraenkel axiomatisation of set theory to be a truth procedure which formed a "condition" for his philosophy. Badiou's relating of philosophy to this axiomatisation of set theory, which appeared as ontology, transformed philosophy into "metaontology". Oliver Feltham, in the Preface to Being and Event,

1 This work was supported by the Czech Science Foundation under the grant: "Unity andMultiplicity in Contemporary Thought”, No. 17-23955S.

2 Alain Badiou, Sometimes, We Are Eternal, Suture Press, Lyon 2019, p. 47.

3 Alain Badiou, Being and Event, trans. Oliver Feltham, Continuum, London and New York 2006, p. xiii.

* Institute of Philosophy of the Czech Academy of Sciences, Prague 
mentioned other axiomatisations of set theory, such as W. V. O. Quine's, and concluded that these multiple axiomatisations show the contingency of philosophy's conditioning. ${ }^{4}$ Badiou's Logics of Worlds was related to a different type of mathematics, i.e. category theory (Samuel Eilenberg and Saunders Mac Lane). The Immanence of Truths draws upon the theory of large cardinals. These various attachments that align philosophy with specific sorts of mathematics seem to be consequences of "axiomatic decisions" which claim no extrinsic justification for themselves. Many scholars assume that axiomatic decisions create the foundations of Badiou's philosophy. ${ }^{5}$ Badiou himself writes that set theory and category theory provide different conditions for philosophy, which instigates "a debate crucial for the construction of the space of philosophy that invariably takes the form of a matrix of ontological choices." ${ }^{6}$ Badiou clearly shows that a mathematical condition of philosophy does not amount to an interpretation of the given state of mathematics that is the business of the philosophy of mathematics - a discipline Badiou rejects. Here, Badiou's crucial idea is that the space of philosophy is "the construction" resulting from philosophical acts that are "ontological choices”. As Norman Madarasz put it, Badiou performs moves in the field of mathematics and makes a decision concerning the relationship among various segments of mathematics.? This decision is not an interpretative choice among various accounts of a part of mathematics that appertains to the philosophy of mathematics, nor does it directly intervene in the field of mathematics so as to develop its axioms, theorems, and techniques. Badiou emphasises that he presents "nothing in mathematics which has not been established." He follows his own philosophical ends and prefers some mathematical axioms and theorems to others. These "ontological choices" are the acts that consistently constitute the mathematical space that conditions philosophy. By these

4 Oliver Feltham, “Translator's Preface”, in Badiou, Being and Event, p. xvii.

5 Zachary Luke Fraser, “New Directions”, in A. J. Bartlett, J. Clemens (eds.), Alain Badiou. Key Concepts. Acumen, Durham 2010, p. 177.

6 Alain Badiou, Mathematics of the Transcendental, trans. A. J. Bartlett and A. Ling, Bloomsbury Publishing, London and New York 2014, p. 16. Category theory is seen to be a complementary theory of set theory. While the latter enables us to conceive a being as a pure multiple, the former provides the topological localisation of a being, or of its appearing in a world.

7 Norman Madarasz, “On Alain Badiou's Treatment of Category Theory in View of a Transitory Ontology”, in G. Riera (ed.), Alain Badiou. Philosophy and Its Conditions, State University of New York Press, Albany 2005, p. 35.

8 Badiou, Being and Event, p. xiv. 
choices Badiou composed a consistent mathematical condition of philosophy. ${ }^{9}$ It means that we divide the mathematical axioms and theorems into two parts. Some are those that we relate to philosophy, the others are those which we leave aside. For this reason, philosophy "constructs" its mathematical condition as a composition of various mathematical fragments. In Manifesto for Philosophy, Badiou defined this role of philosophy as follows: philosophy only composes the given system of its conditions. ${ }^{10}$ Philosophy composes elements given in the field of mathematics so as to construct a consistent scientific condition of philosophy. This philosophical construction consists in selecting axioms, theorems, and techniques such as the axiom of separation, Cohen's generic set, the technique of forcing, etc. These mathematical elements are composed as the conceptual space which philosophy relates itself to. So, we have the selection and composition of the axioms that condition Being and Event. Another selection and composition of mathematical concepts condition Logics of Worlds. Then, there are the ones that create the mathematical condition for The Immanence of Truths. We can see that these conditions are not pre-given but are constructed by philosophy using various mathematical elements. Philosophy, thus, completes a consistent fabric of its condition.

Mathematics is a multiple universe of axioms, theorems, techniques, theories, interpretations, and disputes. Due to this complexity, mathematics as such cannot provide philosophy with a consistent "space" that would condition the development of philosophical concepts. The selection of elements from this immense complexity of mathematics is decisive for the composition of the mathematical condition of philosophy. Needless to say, the composition of the mathematical condition of philosophy is an exacting task. Badiou mentioned that he had been working on set theory for almost twenty years. ${ }^{11}$

9 Badiou noted that he drew on the mathematical material which is dispersed throughout Robert Goldblatt's book Topos: The Categorial Analysis of Logic and throughout other books. He aimed at interpreting mathematical demonstrations such as the one showing that "every 'Boolean' transcendental is expressible in a set-theoretic form, and that, in this sense, there is a kind of legislation of appearing which is isomorphic to that of its being." Badiou, Mathematics of the Transcendental, p. 183.

10 Alain Badiou, Manifesto for Philosophy, trans. N. Madarasz, SUNY Press, Albany 1999, p. 39.

11 Badiou, Sometimes, We Are Eternal, p. 41. 
We will now address Badiou's specific concept of conditioning, which I propose to depict as a three-layered model. Philosophy with its concepts and problems (being, truth, subject, infinity, etc.) forms the top level of this model. The mathematical condition of philosophy is the second level, i.e. the compositive construction produced by philosophy. And finally, the given state of mathematics with its universe of axioms, theorems, lemmas, techniques, etc., represents the third level. Mathematics enables philosophy to construct its own mathematical space, i.e. the second level in the model. So, we have a twofold conditioning. The constructed mathematical space (the second level) conditions philosophy (the first level) and simultaneously the given state of mathematics (the third level) conditions the mathematic space (the second level), providing philosophy with axioms, theorems, etc., to construct it.

Following this introduction, I can present two consecutive theses intended to depict the position of Badiou's philosophy and its dynamic relation to mathematics.

\section{Philosophical concepts as an excess in the metastructure}

The first thesis: the mathematical condition is a "situation", and philosophy acts as its metastructure. Philosophical concepts (event, truth, subject, etc.) appear as a wandering excess from a mathematical point of view. This excess is an effect of the relation between philosophy (metastructure) and its mathematical condition (situation). This excess is described by Easton's theorem.

Žižek maintains that Badiou transposed the real into the discourse of the Master and "what Badiou precludes is the possibility of devising a discourse that has as its structuring principle the unnameable 'indivisible remainder' which eludes a discursive grasp." ${ }^{12}$ Žižek pays attention to the fact that Badiou did not keep the real as an element of a Lacanian discourse, but overlooked another form of the real in Badiou's metaontology which comes to light when we unfold the context of set theory. Badiou conceives of the real as "an impasse of formalisation" which is a result of the operation "the count-as-one", which excludes and

12 Slavoj Žižek, "From Purification to Subtraction: Badiou and the Real”, in P. Hallward, (ed.), Think Again: Alain Badiou and the Future of Philosophy, Continuum, London and New York 2004, p. 177. 
forgets "pure" multiplicities. This exclusion opens lacunae as symptoms of the real in a situation. ${ }^{13}$ In keeping with this meaning of the real, Badiou grasps the real in mathematics as being "deprived of sense." The real is an impasse that makes it impossible to resolve a conflict among interpretations. ${ }^{14}$ We can, therein, find a theorem that conveys the real as being inherent in the representative structure. In the remarkable "Meditation twenty-six" in Being and Event, Badiou shows how the void reappears in the state of a situation, which is a metastructure in the sense of representation, even though the state of a situation had ensured by the operation "the count-as-one" that the void would not be presented.

Badiou draws on Easton's theorem, which states that given an infinite cardinal $\lambda$, the value of a multiple $p(\lambda)$, i.e. the quantity for the state whose situation is the multiple, can be designated as any superior successor cardinal of $\lambda_{.}{ }^{15}$ In Badiou's terms, the state of a situation is quantitatively larger than the situation, but it is impossible to determine the quantitative difference between these two instances. The state of a situation is a representation of the presented situation. From Easton's theorem it follows that representation involves an excess that cannot be counted. We can understand this quantitative excess to be the errant void in the representative structure, the one that corresponds to the real. As Badiou stresses, we have an irremovable rift between the representative structure, i.e. the metastructure, and the situation. This rift produces an un-relation: there is no adequate relation between representation and presentation. In Manifesto for Philosophy, Badiou introduces the un-relation as the real. "This relation has the form of a wandering excess: it is known that the parts are more numerous than the members (Cantor's theorem), but no measure of this 'more' can be established. It is moreover at this real point - wandering excess in the "quantitative' infinite - that the great orientations in thought are established." ${ }^{\prime 6}$

My idea is to conceive of Badiou's philosophy as a representative structure (a metastructure) and its mathematical condition as the presented situation. This interpretation corresponds to Badiou's understanding of the relationship between philosophy and mathematics: philosophy is metaontology and mathe-

13 Badiou, Being and Event, p. 54.

14 Alain Badiou, Briefing on Existence. A Short Treatise on Transitory Ontology, State University of New York Press, New York 2006, p. 56.

15 Badiou, Being and Event, p. 279. Cf. Bartlett et al. (eds.), Badiou. Key Concepts, p. 53.

16 Badiou, Manifesto for Philosophy, p. 80. Easton's theorem refers to Cantor's. 
matics is ontology. Then, Badiou's metaontology can be understood in the light of Easton's theorem, which enables us to elucidate a "quantitative excess" that arises in philosophy as related to mathematics. This excess explains the fact that Badiou's philosophy provides concepts without an adequate relation to mathematical axioms and theorems, even if mathematics is its scientific condition. These concepts appear in the frame of philosophy and form elements that "quantitatively" exceed the ones that we find in the mathematical composition that conditions philosophy. The glaring example of this excess is represented by the concept of an event that is not related to a mathematical axiom. Badiou presents it as "the intervening doctrine" because mathematics is the science of being-qua-being (i.e. ontology), while the doctrine of the event, precisely, designates 'that-which-is-not-being-qua-being' ${ }^{17}$ For this reason, mathematics cannot offer an axiom of the event. Its concept results from the philosophical intervention. The philosophical relation to mathematics is an "un-relation" in this sense. Having an "un-relation” to mathematics as ontology, Badiou's philosophy is not the philosophy of mathematics but a "metaontology" that establishes philosophical concepts without defining their relation to mathematical axioms and theorems.

This "meta-position" means that philosophy "represents" mathematics as ontology. As mentioned above, philosophy composes its condition by selecting some mathematical axioms, theorems, techniques, etc., in order to construct a consistent system thereof that would act as the condition of philosophy. In principle, this procedure corresponds to the operation of "counting" that creates a consistent situation as a "presented multiple."18 The mathematical condition of philosophy works as the "situation" composed by philosophical "counting" consisting in selecting axioms, theorems, etc., from the inconsistent multiplicity of mathematical concepts. ${ }^{19}$ The philosophical "count" simultaneously presents these axioms, theorems, etc., in such a way so as to limit their original mathematical complexity. ${ }^{20}$ This "count" reduces an immense multiplicity of axioms, theorems, and their various formalisations and interpretations. As Badiou put it,

${ }_{17}$ Badiou, Being and Event, p. 13.

18 Ibid., p. 24.

19 Understandably, these axioms, theorems, etc., had been "counted" and presented in the frame of mathematics.

20 For instance, cf. Badiou's philosophical presentation of Cantor's theorem with its original complex formalisation. Ibid., p. 273. 
a metastructure operates in such a way so as to make a situation consistent. ${ }^{21}$ Philosophy itself correspondingly intervenes in the inconsistent multiplicity of axioms, theorems, lemmas, formalisations, systems, etc., that create the universe of mathematics. By this operation, philosophy composes its consistent condition. Therefore, Badiou's philosophy acts as the metastructure that composes its mathematical condition as a consistent multiplicity. Using the proposed model of conditioning, philosophy, being on its top level, represents the metastructure, the constructed mathematical space (the condition of philosophy) on the second level forms a consistent multiplicity, i.e. the presented situation, while mathematics, on the third level, is an inconsistent multiplicity of mathematical axioms, theorems, formalisations, etc. We can conclude: if Badiou's philosophy operates as a metastructure, we can apply Easton's theorem to it.

Easton's theorem shows that Badiou's philosophy as a metastructure involves the wandering excess of representation that cannot be removed. This excess is removable only on the condition that philosophy would lose its position as a metastructure. In this case, philosophy as metaontology would change into the philosophy of mathematics, which does not create specifically philosophical concepts. This excess of representation means that philosophical concepts in the metastructure do not have a defined relation to mathematical axioms. For instance, the concept of the event conveys 'that-which-is-not-being-qua-being' and therefore, it cannot have a defined relation to the mathematical axioms that only cover ontology as a science of being-qua-being. This relation is an "un-relation" that arises as philosophy operates as a metastructure. Easton's theorem helps us to see the meaning of a metastructure regarding philosophy. If philosophy ceased to act as a metastructure, it would lose its position as metaontology. Consequently, philosophy could not deploy specifically philosophical concepts such as event, truth, subject, etc. The concepts with an "un-relation" to mathematics create philosophical elements in the form of a wandering excess, which is the real in the metastructure.

After Badiou established these concepts in the space of set theory, he came to realise that they opened a new philosophical field that could not be covered by set theory. These concepts provoked the problematic of how truths appear in worlds, with many theoretical consequences and resulting issues. This new

${ }^{21} \quad$ Badiou, Being and Event, p. 98. 
field of philosophical investigation could not be deduced from the space of set theory because concepts such as event, truth, and subject, which had opened this new field, have an un-relation to the space of set theory. In Badiou's words, "if the beginning for Being and Event is without philosophy, the consequences of this beginning are, really, within philosophy. In some sense, the movement of the book is from mathematics to something which has no signification from a mathematical point of view." ${ }^{22}$ The philosophical concepts in Being and Event were an excess as seen from the position of set theory. This excess was "wandering" regarding the potentially infinite number of issues, concepts, and interpretations that "event", "truth", and "subject" can generate.

\section{Mathematics and the dynamic dialectics of Badiou's metaontology}

The second thesis: philosophical concepts (event, truth, subject) as an excess in the metastructure open a new philosophical field that is not covered by the given mathematical condition (set theory). Consequently, Badiou composes a mathematical condition (category theory) that enables philosophy to elaborate new concepts (singularity, relation, world). And again, these concepts open another philosophical field with "the immanence of truths", "absoluteness", and "infinity", which call for the composition of a new mathematical condition (large cardinals). This move explains the dialectical dynamics of Badiou's ontology.

From the application of Easton's theorem to Badiou's philosophy as a metastructure it follows that the relation between metaontology and ontology (mathematics) is an un-relation, i.e. a relation that can never be defined. Easton's theorem says that the state of a situation (a metastructure) is quantitatively larger than the situation. As stated above, philosophy as a metastructure generates a possibly infinite number of new issues, concepts, and interpretations, which shows that philosophy (metaontology) is quantitatively larger than its mathematical condition (ontology). Regarding Easton's theorem, it is impossible to determine the quantitative difference between these two instances. To wit, philosophy as a metastructure (metaontology) would always be quantitatively larger than its mathematical condition (ontology), even if we composed this scientific condition of philosophy from any elements of mathematics in any number.

22 Badiou, Sometimes, We Are Eternal, p. 52. 
We saw that the "un-related" philosophical concepts in Being and Event are a wandering excess that opens a new philosophical field with potentially infinite consequences that cannot be covered by means of set theory. In other words, Badiou's philosophy as deployed in Being and Event contains "more" elements than set theory can provide. These excessive elements show lacunae in the given mathematical condition that was composed from the set theoretical elements, i.e. the "situation" on the second level in the model of conditioning. We can explain the dialectical dynamics of Badiou's ontology along these lines. The lacunae in the given mathematical condition of philosophy provoked the construction of a new one that enabled philosophy as a metastructure to develop philosophical possibilities which had emerged in Being and Event. Badiou composed the mathematical condition by adopting some elements of category theory. This composition conditioned the elaboration of philosophical concepts in Logics of Worlds, i.e. singularity, transcendental, object, relation, world, etc. This conditioning is the relation between mathematics and philosophy that can be described as an "un-relation" because philosophy again was a metastructure regarding its mathematical condition composed of elements from category theory (situation). These philosophical concepts were an excess from the point of view of category theory. They opened a new possibility of how to put forward other philosophical concepts such as infinity, absoluteness, and idea. It was necessary to prepare the mathematical space composed of fragments of the theory of large cardinals. This space conditioned the development of the concepts elaborated in The Immanence of Truths. Potentially, these concepts break new ground in other philosophical domains.

Hypothetically, philosophy is step by step going to turn to every field of mathematics that is available. The point is that we will have $a$ lacuna within the mathematical condition even after philosophy composed it from elements of the last field of mathematics remaining. This happens because every section of mathematics is "smaller" than philosophy as a metastructure in which an excessive new philosophical field appears, and the same holds for the last field available. For instance, the concept of infinity in The Immanence of Truths calls for the application of infinity to various forms of politics and economics. Some types of politics and economics proved to be finite, while other types appear to be infinite. In this light, Badiou addresses Marxism by stating that Marxist economics draws on egalitarian principles and opposes the dominant liberal 
economy, which represents the oppression of infinity. ${ }^{23}$ If we were to develop new philosophical concepts in this direction, we would need to compose the scientific condition involving some elements from acceptable "non-mathematical" sciences such as Marxist economics. These are the ones that primarily do not deal with mathematical subject matter (axioms, theorems, hypothesis, etc.), but they apply mathematic formalisation if need be.

I argue that, consistently with Badiou's understanding of philosophy as metaontology, a scientific condition of philosophy can be composed from elements stemming from non-mathematical sciences that embrace mathematic formalisation. These non-mathematical scientific conditions are meant for developing concepts generated by metaontology (Being and Event, Logics of Worlds, The Immanence of Truths), but, principally, they cannot be covered by the mathematical domain only. For instance, the development of political and economic notions that were established by an ontological concept of infinity requires the construction of a scientific condition with elements coming from Marxist economics. Badiou introduced some non-mathematical sciences that operate with mathematic formalisation. These are phonology in linguistics, the foundations of Marxist economics, a part of the anthropological theory of kinship, and a segment of psychoanalysis. These fields are supposed to be exempt from the ideology that largely dominates in the human sciences. ${ }^{24}$ Due to their completely different subject matter, we can put aside phonology and the anthropological theory of kinship. What remains is "the foundation of Marxist economics" and "a segment of psychoanalysis" (i.e. the Lacanian one), which can be conceived as being consistent with Badiou's understanding of philosophy. In The Immanence of Truths, Badiou fully endorses $a$ meaning of Marxist economics and explicitly includes a part of Marxism into his philosophy. Actually, we can see that a part of Marxist economics has formed a condition of Badiou's philosophy in all its development. Badiou only dismissed its other parts, such as "Marxist politics" tied to the state. Alberto Toscano showed that Badiou retained what he regarded as the core Marxist principles. This was "a minimal Marxism that conjoins the political hypothesis of non-domination with the rational identification of the sites of subversion, without thereby committing political practice to

23 Alain Badiou, L'Immanence des vérités, Fayard, Paris 2018, p. 81.

24 Badiou, “Afterword: Some Replies to a Demanding Friend”, in Hallward (ed.), Think Again: Alain Badiou and the Future of Philosophy, p. 234. 
an instrumental, revolutionary or programmatic framework." ${ }^{25}$ This approach to Marxism of Badiou provides a telling example of a non-mathematical condition for the development of philosophy.

Lacanian psychoanalysis works in a similar way in Badiou's philosophy. Badiou embraced some of the key Lacanian notions and their definitions, for instance the real as "the impasse of formalisation." ${ }^{26}$ He elaborated their new meaning within his philosophy, which is another example of how the ontological concepts of truth, infinity, absoluteness, etc., can instigate the development of notions that are related to a non-mathematical domain. So, we have Badiou's concept of the unconscious, i.e. "an inner transcendence of consciousness," which is out of its control regarding the fact that this transcendence is the infinity of a truth procedure. ${ }^{27}$ Badiou speaks about his "vexed, or vexatious, fidelity" to Lacan, which is imprinted in Being and Event and Logics of Worlds. ${ }^{28}$ For Badiou, Lacanian psychoanalysis is the crucial form of anti-philosophy that "aims at an act that it believes is an unconditioned break, a transformation without determination, a groundless leap into the new." ${ }^{29}$ Badiou adopted some elements of Lacanian psychoanalysis in order to compose a condition of philosophy. As Badiou put it, “a contemporary philosopher, for me, is indeed someone who has the unfaltering courage to work through (traverser sans faiblir; literally 'to traverse without weakening') Lacan's anti-philosophy." ${ }^{\circ}$ Here, we have another example of Badiou's composition of a non-mathematical condition of philosophy. Marxism, as much as Lacanian psychoanalysis, represents the non-mathematical sciences that are consistent with Badiou's understanding of philosophy.

25 Alberto Toscano, “Marxism Expatriated: Alain Badiou's Turn”, in J. Bidet and S. Kouvelakis (eds.), Critical Companion to Contemporary Marxism, Brill, Leiden and Boston 2008, p. 533 .

26 This formulation I quoted above appeared as far back as in Theory of the Subject. Alain Badiou, Theory of Subject, trans. B. Bosteels, Continuum, London and New York 2009, p. 23. Here, Badiou declared his commitment to Lacanian psychoanalysis.

27 Badiou, L'Immanence des vérités, p. 188.

28 Alain Badiou, Lacan. Anti-philosophy 3, trans. K. Reinhardt and S. Spitzer, Columbia University Press, New York 2018, p. xl.

29 Ibid., p. xxiv.

30 Ibid. p. xxv. 


\section{Conclusion: mathematics is ontology only if philosophy is metaon- tology}

We determined that Badiou established the relation between philosophy and mathematics that can be understood as the one between a metastructure and a situation. This finding enables us to nuance the statement that mathematics is ontology. René Guitart and other mathematicians understand this statement in such a way that mathematics forms a part of philosophy - sometimes a logical part, sometimes an ontological part. Badiou considers this interpretation false, as he stated that mathematics is different from philosophy. ${ }^{31}$ Mathematics, however, constitutes a condition of philosophy that is a sort of relation. We can interpret this relation as the one between a metastructure and a situation, which shows that mathematics appears as a composed mathematical condition (situation). Metaontological concepts are deployed in philosophy as a metastructure. In keeping with Easton's theorem, these concepts are the excess that emerges in the relation between a metastructure and a situation. They are different from mathematics precisely as a consequence of this type of relation. They are conditioned by mathematics and simultaneously are different from it because they represent an excess from the mathematical point of view.

One of the most stunning features of mathematics is that it supplies a theorem indicating the ontological limits of mathematics itself. Poe was not quite right in writing that mathematics credits its axioms and theorems with "an absolutely general applicability" and presents them as a general truth of the world. Mathematics provides us with a theorem that limits its general applicability.

Mathematics viewed as a multiple universe of all given axioms, theorems, techniques, interpretations, and systems (set theory, category theory, etc.) is not ontology. It is mathematics as the inconsistent multiplicity on the third level in the model of conditioning. Mathematics becomes ontology only if philosophy composes its own scientific condition by using various fragments from mathematics. It is mathematics as the consistent multiplicity on the second level in our model. So, mathematics is ontology provided that philosophy as metaontology has changed mathematics into ontology. To wit, it composed its mathematical condition. Philosophy, thus, manifests that mathematics as a multiple universe

$31 \quad$ Badiou, Sometimes, We Are Eternal, p. 52. 
is not ontology. Philosophy as metaontology shows the ontological limits of mathematics.

\section{References}

Badiou, Alain, "Afterwords: Some Replies to a Demanding Friend", in Think Again: Alain Badiou and the Future of Philosophy, ed. Peter Hallward, Continuum, London and New York 2004

- Lacan. Anti-philosophy 3, trans. K. Reinhard and S. Spitzer, Columbia University Press, New York 2018

- Being and Event, trans. Oliver Feltham, Continuum Books, London and New York 2005

- Briefing on Existence. A Short Treatise on Transitory Ontology, State University of New York Press, New York 2006

- L'Immanence des vérités, Fayard, Paris 2018

- Manifesto for Philosophy, trans. N. Madarasz, SUNY Press, Albany 1999

- Mathematics of the Transcendental, trans. A. J. Bartlett and A. Ling, Bloomsbury Publishing, London and New York 2014

- Theory of Subject, trans. B. Bosteels, Continuum, London and New York 2009

Feltham, Oliver, "Translator's Preface”, in Being and Event

Fraser Zachary, Luke, "New Directions", in Alain Badiou. Key Concepts, ed. A. J. Bartlett, J. Clemens, Acumen, Durham 2010

Madarasz, Norman, "On Alain Badiou's Treatment of Category Theory in View of a Transitory Ontology”, in Alain Badiou. Philosophy and Its Conditions, ed. G. Riera, State University of New York Press, Albany 2005

Toscano, Alberto, “Marxism Expatriated: Alain Badiou's Turn”, in Critical Companion to Contemporary Marxism, ed. J. Bidet and S. Kouvelakis, Brill, Leiden and Boston 2008 Žižek, Slavoj, "From Purification to Subtraction: Badiou and the Real", in Think Again: Alain Badiou and the Future of Philosophy, ed. Peter Hallward, Continuum, London and New York 2004 